\title{
SITUAÇÃO ATUAL E PERSPECTIVAS DO BIODIESEL NO ESTADO DO TOCANTINS
}

\author{
CURRENT SITUATION AND PROSPECTS OF BIODIESEL IN THE STATE
}

OF TOCANTINS

\author{
Abraham Damian Giraldo Zuniga, Aécio Alves Andrade, Giani Raquel dos Santos \\ Resplandes Gouvêa, Laila Cristina Gonçalves Silva Amaral, Layanne Ferreira Sodré, \\ Thiago Silva Novais, Aroldo Arévalo Pinedo e Carla Francisa de Sousa Vieira \\ Universidade Federal do Tocantins - UFT
}

\section{RESUMO}

A produção de biocombustíveis tem sido amplamente debatida no Brasil e no ano de 2014 foi criado o Programa Nacional de Uso e Produção de Biodiesel (PNPB). Este programa busca incentivar uma maior participação de energias renováveis na matriz energética brasileira, com o objetivo de implementar de forma sustentável, técnica, e econômica, a produção e uso do Biodiesel. Além do enfoque na inclusão social e no desenvolvimento regional, via geração de emprego e renda. No panorama nacional, o Estado do Tocantins destaca-se por dispor de uma vasta disponibilidade de terras e apresentar boas perspectivas logísticas devido a implantação de novos modais de transporte. A agricultura familiar é considerada o grande propulsor do agronegócio com, aproximadamente, 45 mil propriedades rurais. Neste contexto, o presente trabalho visa demonstrar os fatores que contribuem com o cenário da produção de biodiesel no Estado do Tocantins.

Palavras chave: Produção; Sustentabilidade; Agricultura familiar; Biocombustíveis.

\begin{abstract}
Biofuel production has been widely debated in Brazil and in 2014 was created the National Program for Production and Use of Biodiesel (NPPB). This program encouraging a greater share of renewable energies in the Brazilian energy matrix, aiming to implement sustainably, technical, and economic , production and use of biodiesel, with a focus on social inclusion and regional development by generating employment and income. On the national scene, the State of Tocantins is distinguished by having a wide availability of land and has good prospects because of logistical deployment of new modes of transportation. Family farming is considered the major driver of agribusiness with approximately 45000 farms. In this context, this paper aims to demonstrate the factors that contribute to the scenario of biodiesel production in the state of Tocantins.
\end{abstract}

Key words: Production; Sustainability; familiar Agriculture; Biofuels.

Recebido em 17/09/2014. Aceito em 14/11/2014. Publicado em 14/01/2015. 


\section{INTRODUÇÃO}

Nas últimas três décadas, a busca por combustíveis alternativos e renováveis ganhou importância devido as crescentes preocupações ambientais e ao esgotamento dos recursos petrolíferos. O biodiesel é recomendado como uma possível substituição do óleo diesel derivado do petróleo, sendo, atualmente, utilizado como mistura em proporções variáveis para motores de combustão interna.

A produção de biodiesel é feita a partir de óleo de origem vegetal ou de gordura de origem animal, por meio de uma reação de transesterificação que ocorre por adição de álcoois (metanol ou etanol). É um combustível oxigenado, renovável, biodegradável e considerado ambientalmente correto.

O Brasil possui uma grande vocação para a produção de biodiesel por dispor de uma ampla variedade de clima e solo, extensa áreas agricultáveis e alta variedade de espécies oleaginosas. O Tocantins, por sua vez, destaca-se no panorama nacional por possuir uma vasta disponibilidade de áreas agriculturáveis e apresentar perspectivas na redução de custos logísticos, a partir da implantação de novos modais de transporte, como a Ferrovia Norte-Sul e a Hidrovia Araguaia-Tocantins,

Atualmente a produção de biodiesel no Estado é realizada por duas usinas, a GRANOL Indústria, Comércio e Exportação S/A, situada em Porto Nacional, e a Companhia Produtora de Biodiesel do Tocantins - BIOTINS Energia, localizada em Paraíso do Tocantins.

O biodiesel é uma alternativa estratégica na matriz energética do Brasil. Aliado ao etanol, florestas energéticas, co-produtos e resíduos agrícolas constitui significativa plataforma da matriz energética com base na biomassa (Mapa, 2006). A relevância destes argumentos é grande, por quantos os biocombustíveis são uma fonte de importância crescente no setor de transportes que representa cerca de um terço das emissões de gases de efeito estufa no mundo (Castro et al., 2010).

Dessa forma, o presente trabalho tem por objetivo elaborar um estudo sobre a situação atual do biodiesel no Tocantins, bem como levantar suas perspectivas futuras de desenvolvimento econômico, social e ambiental da região.

\section{METODOLOGIA}

No presente estudo foram utilizados procedimentos metodológicos explicativo, exploratório e descritivo, fazendo um levantamento dos principais estudos técnicos e 
empíricos sobre o biodiesel no Estado do Tocantins. Os dados para o alcance do objetivo proposto foram coletados em fontes secundárias, como artigos, teses e sítios eletrônicos de instituições renomadas da área de estudo, tais como o Ministério da Agricultura, Pecuária e Abastecimento (MAPA), Agência Nacional do Petróleo, Gás Natural e Biocombustíveis (ANP), Secretaria de Agricultura e Pecuária do Estado do Tocantins (SEAGRO-TO), entre outros, no período de setembro a novembro de 2013.

\section{PRODUÇÃO DE BIODIESEL NO BRASIL}

Com a perspectiva de esgotamento de fontes energéticas de origem fóssil, o aumento do preço e a preocupação com o meio ambiente, as fontes de energias renováveis ganha cada vez mais evidência no cenário mundial. Nesse contexto, o Brasil volta a estimular o programa de produção do biodiesel através de políticas, programas, implantação de leis e incentivo aos produtores rurais.

A Lei 11.097 de 13 de janeiro de 2005 introduziu oficialmente o agrodiesel na matriz energética brasileira. O percentual mínimo obrigatório de adição de agrodiesel ao diesel derivado do petróleo foi fixado em 5\% (B5). Isto é, cada litro de diesel deveria conter 5\% de agrodiesel (Queiroz, 2012).

Desde o lançamento do programa de biodiesel foram realizados doze leilões de biodiesel pela ANP e diversos leilões para formação de estoque pela Petrobras. Estes Leilões de Biodiesel que tem por objetivo conferir suporte econômico à cadeia produtiva do biodiesel e contribuir para o atendimento das diretrizes do PNPB. Os leilões funcionam também como um mecanismo transparente de comercialização além de assegurar a participação da agricultura familiar pois, pelo menos $80 \%$ do volume negociado nos leilões deve ser oriundo de produtores detentores do Selo Combustível Social (Biodiesel, 2014).

O Programa Nacional de Produção e Uso de Biodiesel (PNPB) do Governo Federal, objetiva a implementação de forma sustentável, técnica, e economicamente, da produção e uso do Biodiesel, com enfoque na inclusão social e no desenvolvimento regional, via geração de emprego e renda (Suarez et al., 2006). Por sua vez, instituiu a criação do selo Combustível Social como instrumento para promover a sustentabilidade da agricultura familiar que é um componente que promove a inclusão social e o desenvolvimento regional por meio da geração de emprego e de renda para os agricultores familiares enquadrados nos critérios do Pronaf (Sescoop, 2014). 
O Selo Social é concedido à empresa processadora que adquirir matéria-prima de agricultores familiares, por meio de contrato de compra e venda da produção, com a garantia de assistência técnica aos agricultores. O percentual de obrigatoriedade de aquisição de matéria-prima proveniente da agricultura familiar, necessário à concessão do Selo Combustível Social à empresa produtora de biodiesel (Miki, 2009).

Atualmente existem 68 plantas produtoras de biodiesel autorizadas pela ANP para operação no País, correspondendo a uma capacidade total autorizada de 22.699,06 m3/dia. Destas 68 plantas, 65 possuem autorização para comercialização do biodiesel produzido, correspondendo a $21.245,04 \mathrm{~m}^{3} /$ dia de capacidade autorizada para comercialização. A região norte tem a menor capacidade autorizada, produção mensal e demanda (Tabela 1), em relação às demais regiões (ANP, 2013).

Tabela 1: Capacidade autorizada, produção mensal e demanda compulsória autorizada pela ANP em setembro de 2013.

Table 1: Authorized capacity, monthly production and demand compulsory authorized by ANP in September 2013 .

\begin{tabular}{cccc}
\hline Regiâo & Capacidade autorizada $\left(\mathrm{m}^{3}\right)$ & Produção mensal de biodiesel $\left(\mathrm{m}^{3}\right)$ & Demanda B100 \\
\hline Centro-Oeste & 300.908 & 94.296 & 31.865 \\
Nordeste & 58.804 & 22.345 & 38.861 \\
Norte & 18.600 & 5.117 & 25.292 \\
Sudeste & 94.061 & 19.911 & 107.995 \\
Sul & 219.010 & 111.045 & 46.833 \\
\hline Total & 691.382 & 252.714 & 250.846 \\
\hline
\end{tabular}

Fonte: ANP, 2013.

No Brasil, um dos grandes desafios atuais para a expansão de produção e uso de biodiesel é a disponibilidade de matérias-primas a preços competitivos. E, em face das condições edafoclimáticas distintas das diferentes regiões, a diversificação de culturas agrícolas com adaptação regional (Castro et al., 2010).

No Brasil são realizados financiamentos para pequenos produtores cultivarem plantas oleaginosas para fornecerem matéria prima aos produtores de biodiesel. Dentre todas as oleaginosas a soja é a principal matéria-prima utilizada nas refinarias de biodiesel, atendendo a 72,36\% da produção nacional, seguida pela gordura bovina com 20,68\% (Figura 1). 
Figura 1: Matérias-primas utilizadas para produção de biodiesel no Brasil referência mês de setembro de 2013.

Figure 1: Raw materials used to produce biodiesel in Brazil reference month of September 2013.

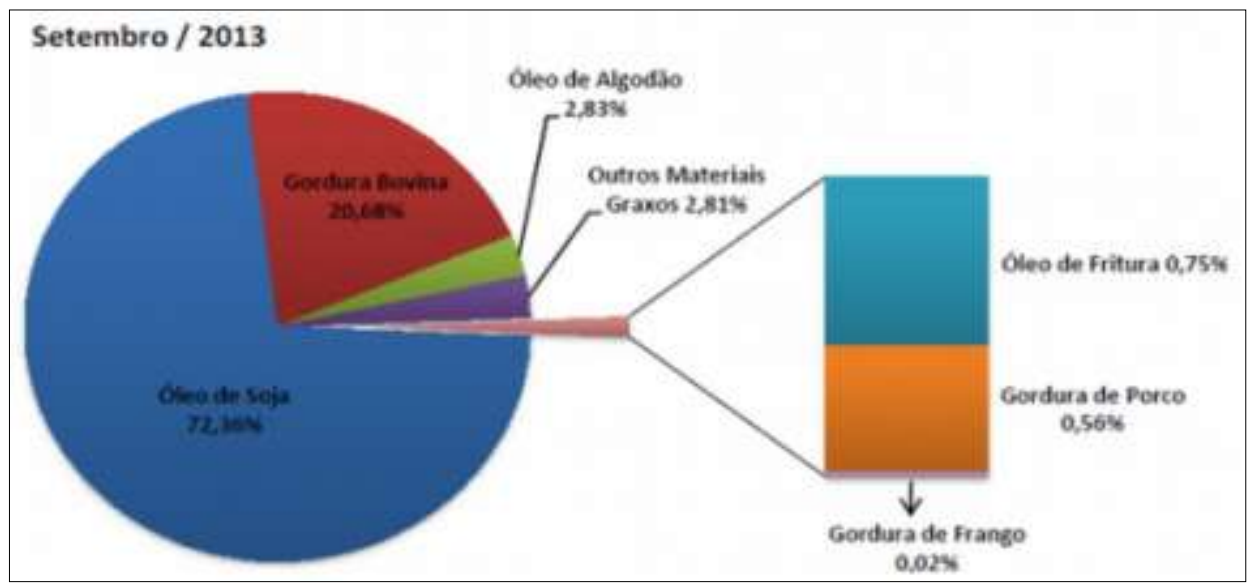

Fonte: ANP, 2013

\section{PRODUÇÃO DE BIODIESEL NA REGIÃO NORTE}

A região Norte possui apenas cinco usinas, a Agroplama, situada no Estado do Pará com capacidade de $80 \mathrm{~m}^{3} / \mathrm{d}$, a Amazonbio e a Ouro Verde, situadas no Estado de Rondônia com capacidade de $90 \mathrm{~m}^{3} / \mathrm{d}$ e $17.000 \mathrm{l} / \mathrm{d}$, respectivamente. No Estado do Tocantins foram implantadas a Granol $\left(360 \mathrm{~m}^{3} / \mathrm{d}\right)$ e a Biotins $\left(81 \mathrm{~m}^{3} / \mathrm{d}\right)$, somando o total de $620 \mathrm{~m}^{3} / \mathrm{d}(\mathrm{ANP}$, 2013). O estado do Tocantins participa com a maior produção de biodiesel em relação aos demais estados da região norte.

As principais matérias-primas utilizadas para produção de biodiesel na região Norte (Figura 2), gordura bovina (12,86\%), outros materiais graxos $(41,75 \%)$ e óleo de soja (45,39\%). A gordura bovina é utilizada para produção de biodiesel durante os onze meses do ano, a soja apenas seis meses (ANP, 2013). Esta particularidade é encontrada apenas na região norte, diferenciando-se das demais regiões brasileiras. 
Figura 2: Matérias-primas utilizadas para produção de biodiesel na Região Norte no período de 2012 a 2013.

Figure 2: Raw materials used for biodiesel production in the North in the 2012-2013 period.

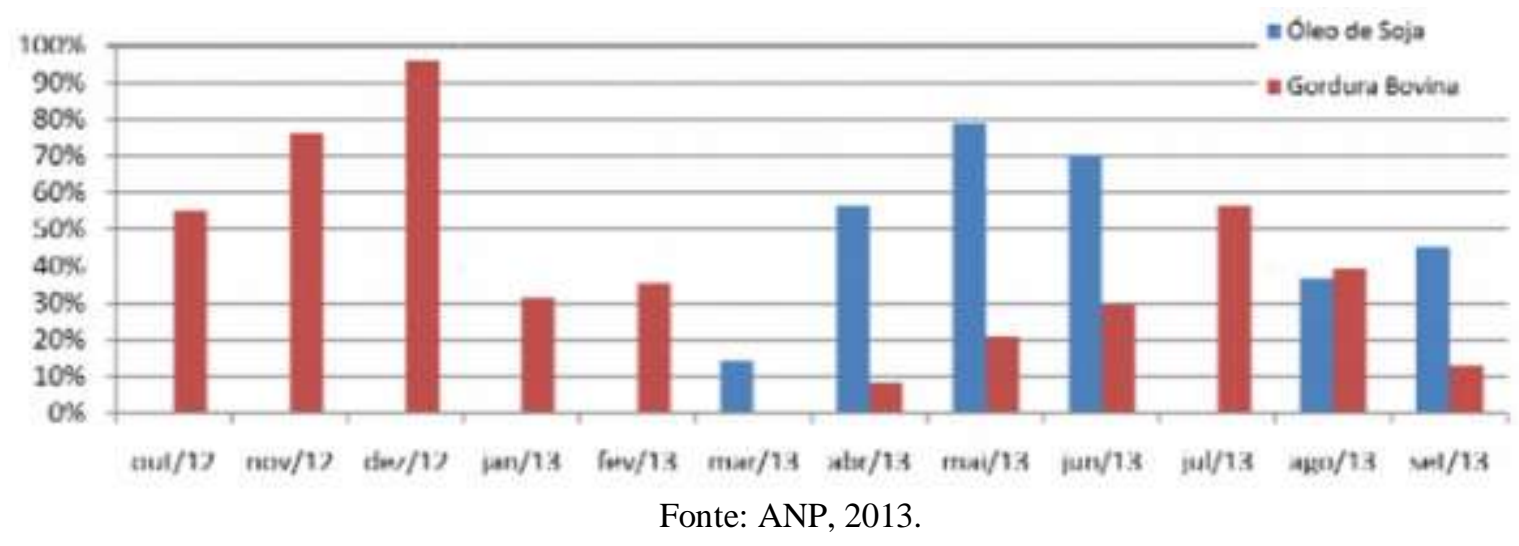

\section{PRODUÇÃO DE BIODIESEL NO ESTADO DO TOCANTINS}

O Tocantins apresenta ótimas condições para o cultivo de oleaginosas que podem ser destinadas a produção de biodiesel. Entre as culturas mais citadas, e das quais já existem experimentos sendo realizados no Brasil, estão a soja, a mamona, o dendê e o girassol. Mas, existem ainda o amendoim, a canola, o coco, o babaçu e o algodão, hoje cultivados com outras finalidades, que também poderão ser aproveitados, pelo menos em parte, na produção de biodiesel. Além destas mais conhecidas, há o pinhão manso, o nabo forrageiro,o pequi, o buriti e a macaúba, com grande potencial.

Figura 3: Distribuição das oleaginosas no estado do Tocantins.

Figure 3: Distribution of oil in the state of Tocantins.

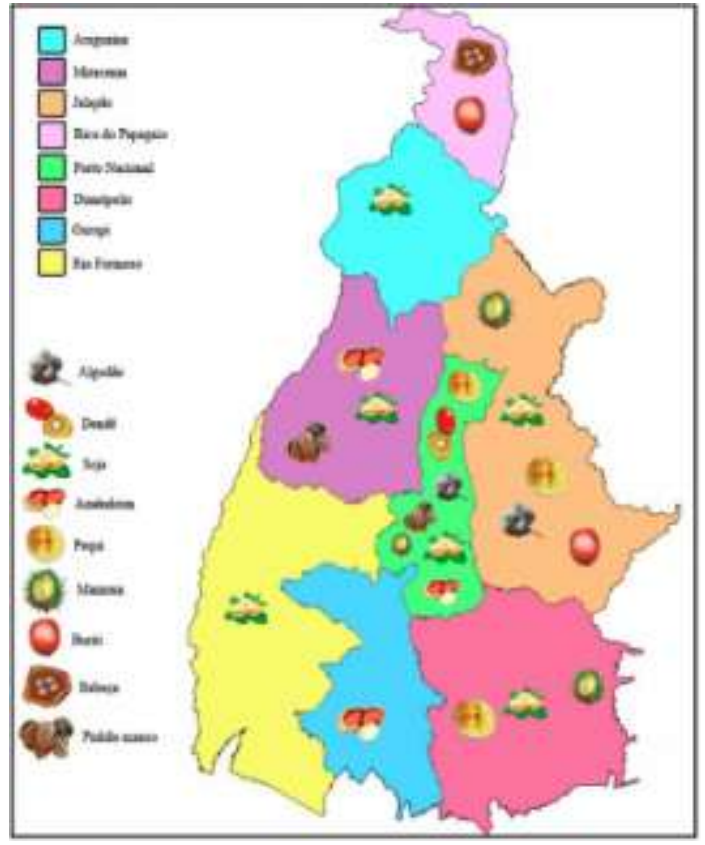

Fonte: Silva et al., 2012 
A soja é a principal matéria prima utilizada para produção de biodiesel no Estado do Tocantins, contudo há também incentivos para o cultivo do amendoim, devido ao seu grande potencial como fonte de energia, pois algumas variedades produzem até $50 \%$ de óleo, enquanto da soja pode-se extrair $20 \%$ de óleo para a fabricação do Biodiesel (Noro et al., 2012). A Secretaria da Agricultura (SEAGRO) tem realizado um trabalho de mobilização, junto às Prefeituras Municipais, para incentivar o plantio dessas oleaginosas nas pequenas propriedades, para aumentar a produção de biodiesel (Rubens, 2013).

\section{ASPECTOS REGULAMENTARES}

O biodiesel foi introduzido na matriz energética brasileira amparada pela Lei $\mathrm{n}^{\circ}$ 11.097/05, aprovada pelo Congresso Nacional em 13 de janeiro de 2005. Como complemento ao marco regulatório do novo segmento, um conjunto de decretos, normas e portarias, que estabeleceram prazo para cumprimento da adição de percentuais mínimos de mistura de biodiesel ao diesel mineral.

Os órgãos reguladores do segmento do biodiesel no Brasil são o Conselho Nacional de Política Energética (CNPE), órgão de assessoramento do presidente da República que tem como prerrogativa formular políticas e diretrizes de energia, o Ministério de Minas e Energia, responsável pela execução da política energética (MME) a Agência Nacional do Petróleo (ANP), Gás e Biocombustíveis, com delegação para regular o mercado do segmento biodiesel com as mesmas funções da regulação, da contratação e da fiscalização das atividades econômicas integrantes da indústria do petróleo, do gás natural e dos biocombustíveis, o Ministério de Desenvolvimento Agrário (MDA), com a missão de conceder o Selo Combustível Social e o Ministério de Agricultura, Pecuária e Abastecimento (MAPA), com a responsabilidade pelo zoneamento agrícola.

O Programa Nacional de Produção e Uso do Biodiesel (PNPB) no Tocantins é executado pela Secretaria de Estado da Agricultura e Pecuária (SEAGRO), a qual faz parte do Grupo Gestor que executa as ações relativas à gestão operacional e administrativa do projeto, conjuntamente com a Empresa Brasileira de Pesquisa Agropecuária (EMBRAPA), o Ministério de Desenvolvimento Agrário MDA, o Serviço de Apoio às Micro e Pequenas Empresas do Tocantins (SEBRAE-TO), o Serviço Nacional de Aprendizagem Industrial do Tocantins (SENAI-TO) e empresas compradoras do biodiesel (Rubens, 2013). 
O Programa de Biodiesel do Tocantins foi lançado no ano de 2005, com a meta de atender cerca de 10 mil famílias integrantes da agricultura familiar, com esse intuito 16 cidades da região central do Tocantins tornaram-se polos de observação e desenvolvimento da cultura da mamona (Biodieselbr, 2014).

Em 2011, com o objetivo de estruturar e incentivar a produção agroenergética no Estado, o Governo do Estado do Tocantins criou o Setor de Agroenergia, estipulando como metas a partir do conhecimento e sistematização de informações, o apoio a pesquisa, a capacitação de técnicos e produtores, a difusão de tecnologias, a desburocratização de processos ambientais, apoio creditícios e a estruturação de polos de produção. Dentre os programas priorizados encontra-se o incentivo a produção de biocombustíveis, como o etanol e o biodiesel (Seagro, 2014).

A criação do curso de mestrado em Agroenergia da Universidade Federal do Tocantins em 2008 também contribuiu para incentivar a produção agroenergética no estado através do fomento à pesquisa.

O Estado do Tocantins possui diversas rodovias federais que se constituem em rotas de escoamento da produção de biocombustíveis, com finalidade para a distribuição interna e principalmente aos portos para exportação. São várias as rodovias que interligam o Estado do Tocantins às outras Regiões brasileiras como: Pará, Maranhão, Goiás, e Bahia. O modal rodoviário é o mais utilizado para o escoamento da produção de biodiesel desta região com destaque para as rodovias BR 153 e BR 010 para o porto do Itaqui localizado no Estado do Maranhão.

Segundo Estados Brasileiros (2014), a Rodovia Belém-Brasília (BR 153) corta o Tocantins de norte a sul, possibilitando um melhor desempenho no crescimento econômico de cidades que ficam a sua margem, além de facilitar o escoamento da produção do Estado para outros Estados e para portos no litoral.

De acordo com Estado do Tocantins (2014), as condições da BR 153 que cruzam o Estado, em sua grande parte se classificam como boa, somente trechos com classificação de atenção. A BR 010 não se encontra com boa classificação, alguns trechos com classificação boa (grande parte) e classificação cuidado e atenção. Além das rodovias BR-153 e BR-010, que necessitam de investimentos para revitalização, destacam-se no corredor do Estado, a Ferrovia Norte-Sul e a Hidrovia Araguaia-Tocantins. Na Tabela 02, estão todas as rodovias que ligam o Estado do Tocantins às outras regiões brasileiras. 
DESAFIOS: Revista Interdisciplinar da Universidade Federal do Tocantins - V. 1, n. 01, p. 263-278, jul/dez. 2014. DOI: http://dx.doi.org/10.20873/uft.2359-3652.2014v1n1p263

Tabela 2: Rodovias que interligam os Estados da Região Centro-Oeste ao resto do País, subdivididas em Radiais, Longitudinais, Transversais e Diagonais.

Table 2: Highways that connect the states of the Midwest to the rest of the country, divided into Radials, Longitudinal, Transverse and diagonals .

\begin{tabular}{ccccc}
\hline & \multicolumn{4}{c}{ Rodovias } \\
\cline { 2 - 5 } & Radiais & Longitudinais & Transversais & Diagonais \\
\hline BR & 10 & 153 & 242 & 352 \\
$\begin{array}{c}\text { Estados } \\
\text { interligados }\end{array}$ & DF, GO, TO, MA, & PA, TO, MG, SP, PR, & TO, BA, MT & MG, GO \\
\hline
\end{tabular}

Fonte: Autor, 2014.

De acordo com Tocantins (2013), "a fácil logística de distribuição (acessos aos portos, hidrovias e ferrovias norte - sul)" "são alguns fatores que favorecem a produção de biodiesel". A exemplo, pode-se observar na Figura 4 a localização dos complexos industriais, unidades armazenadoras, e unidades comerciais da usina GRANOL.

Figura 4: Cidades polos da usina Granol.

Figure 4: Cities poles Granol plant.

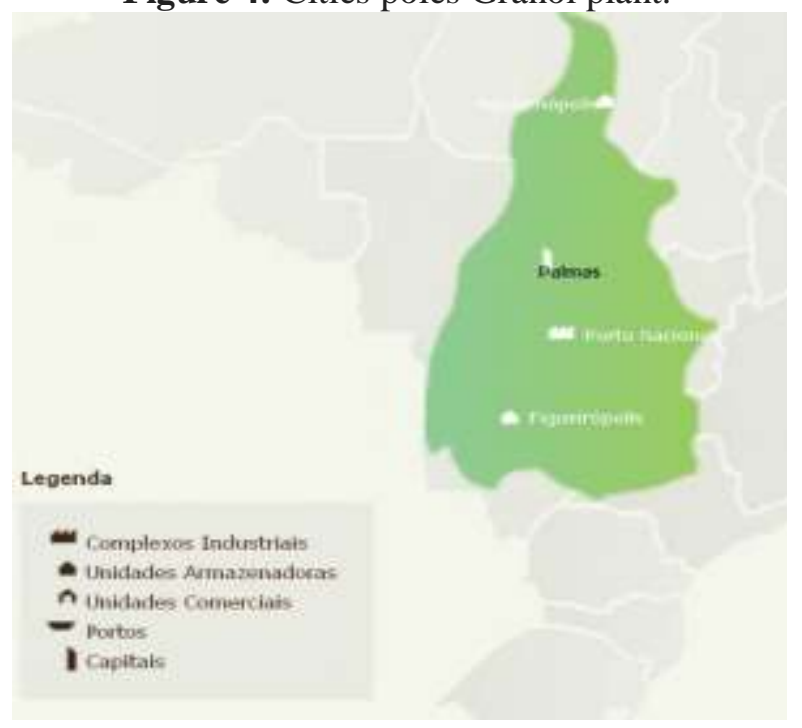

Fonte: Granol, 2014.

\section{ASPECTOS SOCIAIS}

Uma das grandes motivações para a produção de biodiesel são os benefícios sociais que esse biocombustível pode trazer, os quais deverão ser tratados de forma distinta devido à discrepância entre os níveis de desenvolvimento econômico e social dos países (Lima, 2004).

Estudos realizados pelo MDA, MAPA, Ministério da Integração Nacional e Ministério das Cidades apontaram que o processo produtivo do biodiesel trouxe à tona um grande programa de geração de emprego e renda para todo o País (Lima, 2004). 
Estatisticamente e fazendo um comparativo entre a criação de postos de trabalho na agricultura empresarial e na agricultura familiar, esses estudos mostram que a média da agricultura empresarial é de apenas 1 trabalhador para cada 100 hectares cultivados. Na agricultura familiar, por outro lado, a relação passa a ser de 1 trabalhador para cada 10 hectares, mostrando, assim, a importância do Selo Combustível Social ao incentivar e priorizar a agricultura familiar na produção de biodiesel (Biodieselbr, 2014).

No Tocantins, a agricultura familiar é considerada o grande propulsor do agronegócio com, aproximadamente, 45 mil propriedades rurais. Assim, no contexto de inclusão social e geração de emprego e renda, Finco e Doppler (2011) realizaram um estudo onde apresentam essas estatísticas a partir da produção de biodiesel no Tocantins.

Por espécies agrícolas oleaginosas, agriculturas de grande escala, como soja e girassol geram em média 0,05 empregos/ha contra 0,5 das agriculturas de pequena escala, como é o caso da mamona e do pinhão manso. Em nível produtivo, então, a soja e o girassol necessitam de 20 ha para empregar uma família, contra apenas 2 ha no caso da mamona e do pinhão manso (Finco e Doppler, 2011).

Com base nisso, dados referente ao número de empregos e os possíveis postos de trabalho que podem ser gerados mostram que, o pinhão manso possui uma área atual ocupada no Estado de, em média, 500 ha considerando a agricultura familiar e 4 mil ha considerando a empresarial. Assim, a pequena produção de pinhão manso gera, atualmente, 250 empregos, contra 2.000 empregos gerados pela agricultura empresarial no Tocantins, totalizando, assim, 4.500 ha e 2.250 postos de trabalho criados a partir da utilização dessa cultura (Finco e Doppler, 2011).

Quanto à soja, tem-se uma área atual total de 95 mil ha, o que geraria 4.750 empregos, em média, no Estado. Destes, 100\% são de responsabilidade da agricultura empresarial, mostrando, que a agricultura familiar, a partir desta oleaginosa não impacta positivamente no desenvolvimento social do Tocantins (Finco e Doppler, 2011).

Desse modo, observa-se que há grande geração de empregos e renda no Estado a partir da agricultura empresarial e um enorme potencial para o setor da agricultura familiar. A produção de biodiesel a partir de oleaginosas de lavouras familiares e empresariais faz com que esse biocombustível seja uma alternativa importante para a erradicação da pobreza no país, por possibilitar a ocupação de um grande número de trabalhadores, explicando, assim, sobre as razões da inclusão social e do desenvolvimento regional, especialmente via geração de emprego e renda, serem os princípios orientadores básicos das ações direcionadas ao biodiesel (Lima, 2004). 


\section{ASPECTOS AMBIENTAIS}

O consumo de combustíveis fósseis derivados do petróleo impacta significativamente a qualidade do meio ambiente, apresentando, o biodiesel, importante benefícios ambientais. Comparado ao óleo diesel, derivado de petróleo, o biodiesel reduz as emissões dos compostos sulfurados, promove a reciclagem de $\mathrm{CO} 2$ em $78 \%$ a partir da reabsorção pelas plantas, elimina as emissões de óxidos de enxofre em $20 \%$, vez que reduz em $90 \%$ as emissões de fumaças, é biodegradável, tem baixíssima toxidade, é renovável, envia menores teores de materiais particulados, monóxidos de carbono e hidrocarbonetos à atmosfera e, pode ser usado em qualquer motor de ciclo diesel, com pouca ou nenhuma necessidade de adaptação (Andrade filho, 2007).

Para Leonardo Botelho Zílio, um dos coordenadores do Grupo Temático Benefícios Ambientais e Uso de Biodiesel, diversos pontos positivos são disseminados para a sociedade através do setor de biodiesel, principalmente, de cunho ambiental (Brasil, 2013).

Percebe-se, por intermédio da produção e do uso do biodiesel no Brasil, melhorias sensíveis na qualidade do ar respirado nos centros urbanos, bem como nas emissões de gases de efeito estufa. A emissão de materiais particulados e outras substâncias malignas à saúde do ser humano também são reduzidas (Brasil, 2013).

O Tocantins, bem como o Goiás e o Mato Grosso, são vistos por Expedito José de Sá Parente, o 'pai do biodiesel', como celeiros do biodiesel no Brasil em um futuro muito próximo. Para ele, o biodiesel é a oportunidade que o mundo tem para resolver seus problemas ambientais e sociais (Gouveia, 2007).

\section{ASPECTOS ECONÔMICOS}

O Brasil destaca-se no panorama mundial pelo elevado uso de fontes renováveis em sua matriz energética e por ser um dos precursores na criação do biodiesel. No Tocantins, maior produtor de grãos e oleaginosas da região Norte do país, a produção desse biocombustível é impulsionada pelas condições favoráveis que o estado contempla, tais como: abundância dos recursos hídricos, chuvas regulares e a ação política de trazer grandes investimentos para o Estado através de incentivos fiscais e programas que incentivam o processo produtivo na região (Seagro, 2014).

Outros fatores que se apresentam como alternativa para a produção de biodiesel no Tocantins são, principalmente, a disponibilidade de terras e as melhorias das condições 
logísticas, aliada à perspectiva de redução de custos de transportes a partir da implantação de novos modais, tais como a ferrovia Norte-Sul e a hidrovia Araguaia-Tocantins (Rodrigues e Luncke, 2011).

Conforme já citado, existem 68 usinas de produção a nível nacional, com capacidade total de 22.699,06 m³/dia, das quais 5 se encontram na região Norte. Destas, duas situam-se no Estado do Tocantins, são elas: a GRANOL Indústria, Comércio e Exportação S/A, situada em Porto Nacional, possui capacidade de produção de $360 \mathrm{~m}^{3} /$ dia utilizando a rota tecnológica metílica ou etílica, contra $81 \mathrm{~m}^{3} / \mathrm{dia}$, por meio da rota metílica, da Companhia Produtora de Biodiesel do Tocantins - BIOTINS Energia, localizada em Paraíso do Tocantins (ANP, 2013).

Assim, com uma capacidade total autorizada de $158.760 \mathrm{~m}^{3} / \mathrm{ano}$, o Estado do Tocantins foi responsável por apenas $12.000 \mathrm{~m}$ 3/ano de biodiesel vendidos no $33^{\circ}$ Leilão de Biodiesel em 2012, ou seja, apenas 7,56\% de sua capacidade total atual.

Com participação nacional de apenas 2,3\%, a GRANOL S/A, com capacidade de $129.600 \mathrm{~m}^{3} / \mathrm{ano}$, foi responsável pela oferta de $15.000 \mathrm{~m}^{3} /$ dia. Desses, $80 \%$, o equivalente a $12.000 \mathrm{~m}^{3} /$ dia, foram vendidos ao preço de $\mathrm{R} \$ 2,0877 /$ litro, gerando uma receita de $\mathrm{R} \$ 23.052 .130$ para o Estado (ANP, 2013).

Para a BIOTINS Energia, com capacidade de $29.160 \mathrm{~m} / \mathrm{ano}$ e oferta de $2.000 \mathrm{~m}^{3}$, os resultados foram ainda piores, vez que sua participação no $33^{\circ}$ Leilão foi de $0 \%$. Isso pode ser explicado pelo fato de que a BIOTINS, por não conseguir apresentar preços tão atrativos frente às demais participantes do leilão, preferiu deixar seu produto em estoque para revenda a vender a preços baixos e obterem prejuízos ainda maiores (ANP, 2013).

Durante o ano de 2012, o Estado do Tocantins foi considerado o nono maior produtor de biodiesel no Brasil, com produção de 445.650 barris equivalentes de petróleo (bep), ficando a frente de Santa Catarina, Rio de Janeiro, Ceará, Maranhão, Pará e Rondônia. Em 2013, mais especificamente, até o mês de setembro, observa-se na Tabela 4 que o Estado está perdendo sua posição para o Ceará, encontrando-se na décima colocação com capacidade produtiva de 204.580 bep, atrás de estados como Rio Grande do Sul, Goiás, Mato Grosso, Bahia e Paraná. 
Tabela 3: Produção nacional de biodiesel por grandes regiões e ranking por estados brasileiros produtores de biodiesel, em bep.

Table 3: National Biodiesel Production by regions and by ranking Brazilian states biodiesel producers in boe .

\begin{tabular}{|c|c|c|c|c|}
\hline Ano & 2012 & Ranking 2012 & 2013* & Ranking 2013 \\
\hline SUL & 5.878 .419 & & 5.194 .379 & \\
\hline Santa Catarina & - & $13^{\circ}$ & 115.898 & $11^{\circ}$ \\
\hline Paraná & 761.983 & $06^{\circ}$ & 874.404 & $05^{\circ}$ \\
\hline Rio Grande do Sul & 5.116 .436 & $01^{\circ}$ & 4.204 .077 & $01^{\circ}$ \\
\hline SUDESTE & 1.622 .368 & & 1.218 .524 & \\
\hline Minas Gerais & 508.155 & $08^{\circ}$ & 430.273 & $08^{\circ}$ \\
\hline Rio de Janeiro & 108.139 & $11^{\circ}$ & 39.360 & $13^{\circ}$ \\
\hline Sāo Paulo & 1.006 .074 & $05^{\circ}$ & 748.891 & $07^{\circ}$ \\
\hline CENTRO-OESTE & 7.377 .521 & & 5.604 .573 & \\
\hline Goiás & 3.813 .671 & $02^{\circ}$ & 2.735 .774 & $02^{\circ}$ \\
\hline Mato Grosso & 3.030 .612 & $03^{\circ}$ & 1.996 .153 & $03^{\circ}$ \\
\hline Mato Grosso do Sul & 533.238 & $07^{\circ}$ & 872.646 & $06^{\circ}$ \\
\hline NORDESTE & 1.862 .428 & & 1.421 .080 & \\
\hline Bahia & 1.466 .760 & $04^{\circ}$ & 1.011 .415 & $04^{\circ}$ \\
\hline Ceará & 395.668 & $10^{\circ}$ & 409.665 & $09^{\circ}$ \\
\hline Maranhāo & - & $14^{\circ}$ & - & $14^{\circ}$ \\
\hline NORTE & 498.979 & & 264.207 & \\
\hline Pará & - & $15^{\circ}$ & - & $15^{\circ}$ \\
\hline Rondônia & 53.329 & $12^{\circ}$ & 59.627 & $12^{\circ}$ \\
\hline Tocantins & 445.650 & $09^{\circ}$ & 204.580 & $10^{\circ}$ \\
\hline TOTAL & 17.239 .715 & & 13.702 .764 & \\
\hline
\end{tabular}

* Dados contabilizados até setembro de 2013.

Fonte: Modificada ANP, 2013.

Além disso, quanto à capacidade de produção autorizada pela ANP, o Tocantins está classificado na $10^{a}$ posição até setembro de 2013 , com mais de $441 \mathrm{~m}^{3} /$ dia. Para se ter uma noção comparativa, o primeiro lugar foi do Rio Grande do Sul, responsável por mais de $5.677,33 \mathrm{~m}^{3} /$ dia de capacidade produtiva (ANP, 2013).

\section{CONCLUSÃO}

A perspectiva de esgotamento de fontes energéticas de origem fóssil, vem impulsionando as fontes de energias renováveis e a produção de biodiesel. O Estado do Tocantins tem diversos fatores que proporcionam a produção de biodiesel como extensas áreas agricultáveis, matéria prima abundante, solo e clima extremamente favoráveis, e uma fácil logística de distribuição. Atualmente temos várias pesquisas em andamento em Universidades, Institutos e empresas incentivados pelo Setor de Agroenergia criado em 2011. A agricultura familiar vem sendo considerada o grande propulsor do agronegócio. Quanto aos aspectos ambientais e sociais o biodiesel é a oportunidade que o mundo tem para resolver seus problemas no âmbito ambiental e social. 


\section{REFERÊNCIA BIBLIOGRÁFICA}

ANP- Agência Nacional do Petróleo, Gás Natural e Biocombustíveis. Boletim mensal dos biocombustíveis: outubro de 2013. 2013.

ANP. Agência Nacional do Petróleo, Gás Natural e Biocombustíveis - Boletim mensal dos combustíveis renováveis: outubro de 2013. 2013.

ANDRADE FILHO, M. Aspectos técnicos e econômicos da produção do biodiesel: o caso do sebo bovino como matéria-prima. 2006. 124 f. Dissertação (Mestrado em Regulação da Indústria de Energia) - Programa de Pós-Graduação em Energia, Universidade Salvador, Salvador. 2007.

BIODIESEL. Programa Nacional de Produção e Uso de Biodiesel. Disponível em: < http://www.mme.gov.br/programas/biodiesel>. Acesso em: 13/09/2014.

BIODIESELBR. Agricultura familiar, emprego e o lado social do biodiesel. Disponível em: $<\quad$ http://www.biodieselbr.com/biodiesel/social/aspectos-sociais.htm>. Acesso em: 04/08/2014.

BRASIL. Ministério da Agricultura, Pecuária e Abastecimento. Estudo trata do benefício ambiental com uso de biodiesel. Brasil. 2013.

CASTRO, A. M. G. et al. Complexo Agroindustrial de Biodiesel no Brasil.: Competitividade das Cadeias Produtivas de Matérias-Primas. Brasília-DF. Embrapa Agroenergia, 2010

ESTADOS BRASILEIROS. Tocantins. Disponível em: <http://www.portalbrasil.net/estados_to.htm> Acesso em: 05/09/2014.

ESTADO DO TOCANTINS. Condições das Rodovias. Disponível em: <www2.transportes.gov.br/bit/02-rodo/4-cond-rodo/to.pdf> Acesso em: 05/09/2014.

FINCO, M. V. A. e DOPPLER, W. Biodiesel e Desenvolvimento Regional na Amazônia Legal: casos do Estado do Tocantins. Amazônia (Banco da Amazônia. 2005), v. 6, p. 7-27, 2011.

GOUVEIA, J.. Inventor do biodiesel diz que Tocantins é celeiro do combustível. Agência Tocantinense de Notícias. Palmas. 2007.

GRANOL. Disponível em: <http://www.granol.com.br/granol/onde+estamos/\#> Acesso em: 05/09/2014.

LIMA, P. C. R.. O Biodiesel e a Inclusão Social. Biblioteca Digital da Câmara dos Deputados. Centro de Documentação e Informação. Coordenação de Biblioteca, 2004.

MAPA - Ministério da Agricultura, Pecuária e Abastecimento. Plano Nacional de Agroenergia 2006-2011. 2. ed. Brasília, DF: Embrapa Informação Tecnológica, 2006. 110 p.

MIKI, A. F.C. Programa Nacional de Produção e Uso do Biodiesel -PNPB: Do discurso à prática. Dissertação de Mestrado. Programa de Mestrado em Geografia. Universidade Federal de Rio Grande, Rio Grande, 2009.

NORO, G. B. NORONHA, K. B. FROZZA, M. LENGLER, L. Análise de práticas sustentáveis na produção de biodiesel: um estudo de caso. IX SEGeT - Simpósio de Excelência em Gestão e Tecnologia, 2012.

QUEIROZ, T. L. B. de. Produção de agrodiesel na Paraíba: avanço do agronegócio das oleaginosas, movimentos sociais e soberania alimentar . Dissertação de Mestrado. Programa de Pós-Graduação em Geografia. Universidade Federal da Paraíba. João Pessoa, 2012.

RODRIGUES, W. e LUNCKES, J. F.. Rentabilidade Econômica da Produção de Biodiesel de Mamona no Estado do Tocantins. Custos e Agronegócio Online, v. 7, p. 36-64, 2011.

RUBENS, A. Agricultores familiares impulsionam produção de biodiesel no Tocantins. Tocantins agora. Palmas, 2013. 
SEAGRO - Secretaria da Agricultura e Pecuária. Agroenergia. Disponível em: <www.seagro.to.gov.br>. Acesso em: 06/09/2014.

SESCOOP - Serviço Nacional de Aprendizagem do Cooperativismo. A inserção das cooperativas no processo de produção de Biodiesel. 2008. Disponível em: <www.brasilcooperativo.coop.br>. Acesso em: 23/08/2014.

SIlva, F. A. L. SOUTO, S. B. G. AlviM, J. C. COllicChiO, E. AlviM, T. C. Distribuição geográfica das oleaginosas no Estado do Tocantins com potencial para uso para produção de biodiesel. Anais do I Simpósio Nacional de Agroenergia, 2012.

SUAREZ, P. A. Z. et al. O biodiesel e a política de C \& T brasileira. Química Nova [online], v. 29, n. 6, p. 1157-1157, 2006.

TOCANTINS - O bioestado perfeito! Disponível em: <http://www.biotins-energia.com.br/> Acesso em: 15 nov. de 2014.

\section{Abraham Damian Giraldo Zuniga}

Possui graduação em Engenharia de Alimentos (diploma revalidado pela Universidade Federal de Viçosa - MG) mestrado em Ciência e Tecnologia de Alimentos pela Universidade Federal de Viçosa (2000) e doutorado em Ciência e Tecnologia de Alimentos pela Universidade Federal de Viçosa (2003). Pôs doutorado em Biotecnologia (2012). Atualmente é professor Associado II da Universidade Federal do Tocantins Curso de Engenharia de Alimentos. Atua como professor efetivo do curso de mestrado em Ciência e Tecnologia de Alimentos, mestrado de Agroenergia da Universidade Federal do Tocantins e Doutorado em Biodiversidade e Biotecnologia da rede Bionorte-UFT. Tem experiência na área de Ciência e Tecnologia de Alimentos, com ênfase em Operações de Separação e Mistura, atuando principalmente nos seguintes temas: desidratação, biotecnologia e biocombustiveis.

E-mail: abraham@mail.uft.edu.br

Endereço: Programa de Pós-graduação - Mestrado em Ciência e Tecnologia de Alimentos 109 Norte Av. NS-15, ALCNO-14. Plano Diretor Norte. CEP: 77001-090.

\section{Aécio Alves Andrade}

Mestrando em Agroenergia pela Universidade Federal do Tocantins - UFT.

E-mail: aecio@gmail.com

Endereço: Programa de Pós-graduação - Mestrado em Ciência e Tecnologia de Alimentos 109 Norte Av. NS-15, ALCNO-14. Plano Diretor Norte. CEP: 77001-090.

\section{Giani Raquel dos Santos Resplandes Gouvêa}

Mestre em Agroenergia pela Universidade Federal do Tocantins (2015). Possui graduação em Direito pelo Instituto de Ensino e Pesquisa Objetivo (2011). Com experiência de 16 anos em análises laboratoriais, exerce o cargo Técnico em Laboratório na Universidade Federal do Tocantins, Campus Universitário de Palmas, com lotação no Laboratório de Sistemas de Produção de Energias a partir de Fontes Renováveis - LASPER; realizando análises relacionadas à produção de etanol a partir de matérias primas renováveis, tais como, amido, açúcares redutores totais, fermentação biológica e destilação; análises da qualidade de etanol. Possui habilidade técnica no processamento e extração de etanol e seus derivados. Atuante na área de Propriedade Intelectual, Inovação e Desenvolvimento Tecnológico.

E-mail: giane@gmail.com

Endereço: Programa de Pós-graduação - Mestrado em Ciência e Tecnologia de Alimentos 109 Norte Av. NS-15, ALCNO-14. Plano Diretor Norte. CEP: 77001-090. 


\section{Laila Cristina Gonçalves Silva Amaral}

Graduada em Ciências Econômicas pela Universidade Federal do Tocantins - UFT. Durante a graduação foi bolsista do Programa de Educação Tutorial do Curso de Ciências Econômicas por 2 anos e, atualmente, é mestranda em Agroenergia pela Universidade Federal do Tocantins - UFT e bolsista do CNPQ.

E-mail: lcristina@gmail.com

Endereço: Programa de Pós-graduação - Mestrado em Ciência e Tecnologia de Alimentos 109 Norte Av. NS-15, ALCNO-14. Plano Diretor Norte. CEP: 77001-090.

\section{Layanne Ferreira Sodré}

Mestrando em Ciência e Tecnologia de Alimentos.

E-mail: layanne@gmail.com

Endereço: Programa de Pós-graduação - Mestrado em Ciência e Tecnologia de Alimentos 109 Norte Av. NS-15, ALCNO-14. Plano Diretor Norte. CEP: 77001-090.

\section{Thiago Silva Novais}

Mestrando em Ciência e Tecnologia de Alimentos pela Universidade Federal do Tocantins. Possui graduação em Engenharia de Alimentos pela Universidade Federal do Tocantins (2013). Participou do Programa Institucional de Bolsas de Iniciação Científica - PIBIC atuando nas linhas de pesquisas de desidratação de frutas, cinética de secagem e aproveitamento de subprodutos alimentícios.

E-mail: thiagosilvanovais@gmail.com

Endereço: Programa de Pós-graduação - Mestrado em Ciência e Tecnologia de Alimentos 109 Norte Av. NS-15, ALCNO-14. Plano Diretor Norte. CEP: 77001-090.

\section{Aroldo Arévalo Pinedo}

Possui graduação em Engenharia em Indústrias Alimentarias pela Faculdade de Engenharia em Indústrias Alimentarias da Universidad Nacional de la Amazónia Peruana - Perú (1992), Mestrado em Engenharia de Alimentos pela Universidade Estadual de Campinas UNICAMP (1995) e Doutorado em Engenharia de Alimentos pela Universidade Estadual de Campinas UNICAMP (2003). Atualmente é professor Associado III da Fundação Universidade Federal do Tocantins (UFT) no Curso de Engenharia de Alimentos. Tem experiência na área de Ciência e Tecnologia de Alimentos, com ênfase em Ciência e Tecnologia de Alimentos, atuando principalmente nos seguintes temas: processamento de frutas e hortaliças, secagem de alimentos, medidas de propriedades físicas de alimentos.

E-mail: aroldo@uft.edu.br

Endereço: Programa de Pós-graduação - Mestrado em Ciência e Tecnologia de Alimentos 109 Norte Av. NS-15, ALCNO-14. Plano Diretor Norte. CEP: 77001-090.

\section{Carla Francisa de Sousa Vieira}

Possui graduação em Licenciatura em matemática pelo Instituto Federal de Educação, Ciência e Tecnologia do Tocantins (2013) e graduação em Engenharia de Alimentos pela Fundação Universidade Federal do Tocantins (2008). Atualmente é tecnico em laboratório da Fundação Universidade Federal do Tocantins.

E-mail: carla@mail.uft.edu.br

Endereço: Programa de Pós-graduação - Mestrado em Ciência e Tecnologia de Alimentos 109 Norte Av. NS-15, ALCNO-14. Plano Diretor Norte. CEP: 77001-090. 